\title{
Roberto Schwarz e a interpretação crítica do Brasil
}

[ Roberto Schwarz and the critical interpretation of Brazil

Maria Arminda do Nascimento Arruda ${ }^{\mathrm{I}}$

Recebido em 5 de novembro de 2019

Aprovado em 20 de novembro de 2019

ARRUDA, Maria Arminda do Nascimento. Roberto Schwarz e a interpretação crítica do Brasil. Revista do Instituto de Estudos Brasileiros, Brasil, n. 74, p. 27-32, dez. 2019.

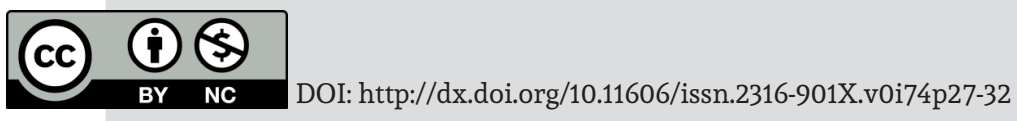

I Universidade de São Paulo (USP, São Paulo, SP, Brasil). 
Transcorridos mais de quarenta anos desde o lançamento do livro Ao vencedor as batatas - forma literária e processo social nos inícios do romance brasileiro, cuja primeira edição data de I977, a obra do intelectual e crítico Roberto Schwarz é novamente objeto de reflexão sistemática. Outra iniciativa similar à deste Dossiê da Revista do Instituto de Estudos Brasileiros - que ora publica os trabalhos apresentados em seminário acontecido há dois anos ${ }^{2}$ - teve origem em evento organizado na Universidade de São Paulo em 2004, cujas contribuições foram posteriormente reunidas em coletânea editada em 2007 (CEVASCO; OHATA, 2007). Nesse lapso de mais de quarenta anos, persistem traços comuns aos textos das duas publicações, que distinguem o papel de Schwarz no entendimento da cultura e da vida intelectual no Brasil, análises que reafirmam o caráter fundamental da sua reflexão tanto à compreensão das contradições presentes na experiência social periférica, quanto à caracterização dos dilemas e impasses que teimam desafiar o exercício intelectual esclarecido nas sociedades marginalizadas das conquistas modernas.

$\mathrm{Na}$ introdução do livro clássico, o autor afirma pretender "especificar um mecanismo social, na forma em que ele se torna elemento interno e ativo da cultura; uma dificuldade inescapável, tal como o Brasil a punha e repunha aos seus homens cultos, no processo mesmo de sua reprodução social. Noutras palavras, uma espécie de chão histórico, analisado, da experiência intelectual” (SCHWARZ, I977, p. 24). Entre as duas publicações acima aludidas, artigos e comentários de vária ordem vieram à luz nos mais diversos meios, desde obras acadêmicas e especializadas, até veículos da grande imprensa. No conjunto, e independentemente da origem disciplinar dos autores, a volumosa produção do intelectual paulista é unanimemente reconhecida como sendo de grande envergadura, seja no campo da crítica da literatura, seja na área do ensaísmo crítico, seja ainda no âmbito das análises culturais e das conjunturas político-ideológicas do país. Nesse sentido, a produção multifacetada de Schwarz desborda o terreno da crítica literária e cultural, erigindo-se em

2 O Seminário "40 anos de Ao vencedor as batatas, de Roberto Schwarz" foi organizado pela Faculdade de Filosofia, Letras e Ciências Humanas da Universidade de São Paulo (FFLCH/USP) de I2 a I5 de setembro de 2017. 
instrumento essencial à análise das formas assumidas pela modernidade periférica, especialmente em realizações históricas como a brasileira.

Esse caráter abrangente da sua obra, que explica, em larga medida, o constante interesse das novas gerações por sua trajetória, não parece suficiente para garantir a persistência de estudos sobre ela ao longo de quase meio século, a exemplo deste número especial da Revista do Instituto de Estudos Brasileiros. Sintoma de atualidade da reflexão do autor e da sua capacidade de construir um modo próprio de combinar refinamento analítico, engajamento político, crítica social, sem abandonar as dimensões formais subjacentes à matéria analisada. Nos dizeres do seu mestre Antonio Candido, "Roberto Schwarz [...] é capaz de situar-se de várias maneiras e em vários níveis dentro e fora do texto, percebendo tanto a sua autonomia como construção específica quanto a sua dependência como produto cultural, além de possuir a capacidade de elaborar o estilo adequado para sugerir esta posição" (CANDIDO, 2007, p. I4-I5). Mais adiante, acrescentou:

É basicamente ensaísta, mas um ensaísmo que modificou a crítica brasileira, na medida em que superou o tom de fluência jornalística, que foi sempre o nosso melhor modo de trabalhar, num país que só teve crítica universitária depois que o ensino superior de literatura começou e deu os primeiros resultados, isto é, a partir do decênio de I940. Roberto Schwarz não embarcou na tonalidade jornalística, nem aderiu aos tecnicismos que as nossas letras universitárias adotaram frequentemente com o alvoroço dos neófitos. (CANDIDO, 2007, p. I5).

Essa qualidade de preservar a integridade do material em escrutínio, sem abandonar o seu sentido social, sugere interpretações da sua obra em múltiplas leituras, oriundas de distintas filiações disciplinares. Crítico da cultura, Schwarz é intérprete sagaz dos rumos assumidos pela ordem burguesa entre nós, presentes no descolamento entre os valores típicos da classe e os móveis efetivos das práticas sociais. O desconcerto resultante - fruto da debilidade dos atores em superar as forças do passado, que contrariamente a elas se mesclam - responde pelo desacordo permanente da história brasileira nas esferas política, social e cultural, cujo "chão social é de consequência para a história da cultura” (SCHWARZ, I977, p. 23). Nesse andamento, por intermédio da análise da literatura de Machado de Assis, Schwarz expõe o deslocamento do ideário liberal recebido da Europa em uma sociedade escravista, criando uma "comédia ideológica diferente da europeia", cujo conflito encontrava acomodação na "prática geral do favor" (SCHWARZ, I977, p. I4).

A maneira surpreendente de encaminhar o problema é revelação da originalidade do pensamento schwarziano, evidente na plasticidade do manejo da teoria social, qualidade que ele próprio atribui ao seu mestre:

Entretanto, ao assumir resolutamente o valor de uma experiência cultural de periferia, ao não abrir mão dela, Antonio Candido chegava a um resultado de peso, que de periférico não tem nada: a universalidade das categorias dos países que nos servem de modelo não convence e a sua aplicação direta aos nossos é um equívoco. (SCHWARZ, 2OI2, p. 49). 
Frente às ambiguidades do tecido social, o intelectual da periferia do mundo é compungido a despender esforços redobrados e a reconstruir de modo autônomo as teorias, como assinalou Antonio Candido no texto de homenagem a Schwarz:

Um intelectual europeu podia ser apenas ele, encasulado na sua língua e na sua civilização, só se reportando, fora delas, à tradição greco-latina. Mas um intelectual latino-americano tinha que ser ele e mais um outro. Esse outro era a quota da cultura europeia da qual necessitava para se formar. (CANDIDO, 2007, p. I5).

Para Candido, Schwarz vivenciou de modo particular a necessidade de incorporar o externo. Dada a sua dupla condição de europeu de nascimento, formado num ambiente culto, e brasileiro por adoção e escolha, o outro está "incrustrado nele" e mantido em convivência harmônica. Com tais afirmações, Antonio Candido sugere que a força do pensamento de Schwarz deriva dessa conciliação singular, trabalho difícil e penoso para os intelectuais de países periféricos, que comumente oscilam entre a assimilação acrítica de teorias forâneas e o mergulho no provincianismo reinante.

Nesse cenário, a obra de Roberto Schwarz erige-se em guia para sucessivas gerações, hodiernamente compungidas à vivência no exterior e a produzir trabalhos articulados às redes internacionais de pesquisa. Em função da sua abrangência analítica, a contribuição schwarziana faculta a formulação de perguntas provenientes de tradições disciplinares particulares e permite perscrutar problemas variados de reflexão, integrados, porém, ao todo social. A interpretação apurada instituiu uma modalidade de compreensão da sociedade moderna no país, expressa no caráter enviesado da ordem burguesa que se imiscui na cultura e ocupa a esfera ideológica de nossas sociedades, cujos efeitos deletérios reproduzem-se no tempo. Finalmente, por eleger a esfera cultural como lugar privilegiado para analisar a dinâmica do conjunto, afirma o caráter decisivo da crítica como procedimento adequado ao pensamento, mormente em contextos desafinados em relação aos centros intelectuais hegemônicos. Nesse cenário, a importância da obra de Roberto Schwarz pode ser mais bem apreciada quando se consideram as recorrentes publicações que sobre ela se debruçaram.

A presente edição distingue-se das demais por agregar, ao rol dos estudos existentes, contribuições da nova geração de pesquisadores, à exceção do trabalho de Maria Elisa Cevasco e da participação como coautor de Francisco Alambert. A despeito da diversidade dos temas e consciente do risco de arbitrariedade que ronda as classificações, creio ser possível agrupar os onze textos que compõem o Dossiê em três grandes áreas temáticas: estudos sobre a contribuição crítica; herança modernista e crítica literária; abordagens teóricas, diálogos e filiações intelectuais. Certamente, o conjunto das análises que escandem o escopo analítico e político das interpretações de Schwarz sobre o processo de formação e de reprodução da ordem capitalista no Brasil sobreleva o ponto de vista da crítica da cultura. Dessa forma, embora o seminário que deu origem aos textos em epígrafe celebrasse os quarenta anos de Ao vencedor as batatas, os trabalhos abrangeram outras contribuições e enfrentaram questões que ultrapassaram o universo particular da obra.

Os artigos que se dedicaram aos pressupostos da crítica salientaram a particular renovação das categorias analíticas concebidas na tradição da dialética materialista, 
manifesta no seu alcance cognitivo para elucidar as contradições do Brasil contemporâneo, a exemplo do texto "O trabalho da crítica”, de Maria Elisa Cevasco. Na mesma vertente, em "Ambivalências da derrota: lições e limites da crítica do populismo em Roberto Schwarz”, de Pedro Luiz Lima, explorou-se a capacidade da produção do autor na compreensão das derrotas civilizatórias, tendo como pano de fundo o populismo na política brasileira. Embora o texto de Lidiane Soares Rodrigues - "As regras da subversão: Roberto Schwarz, Bertha Dunkel e a revista Teoria e Prática” - seja mais específico vis-à-vis os demais, pois analisou a construção da personagem-pseudônimo Bertha Dunkel, que veio à luz nas páginas da revista Teoria e Prática, uma espécie de alter ego de Schwarz, a autora elegeu esse momento pouco visitado, espécie de "ponto cego da discussão sobre a obra de Roberto Schwarz", visto como fundamental ao andamento de futuros ensaios.

Os textos sobre a crítica literária e o modernismo são desdobramentos dos anteriores, apesar da ênfase no papel das vanguardas na modelagem da obra de Schwarz. Bruna Della Torre, em "Modelos críticos: Antonio Candido e Roberto Schwarz leem Oswald de Andrade”, tratou da herança oswaldiana no pensamento dos dois críticos, derivada das leituras sobre o modernismo. Em "Dois críticos, uma semana, um século”, Francisco Alambert e Tiago Ferro correlacionaram o tratamento da forma literária em contextos periféricos aos desdobramentos do modernismo; no artigo "De modernidades periféricas: feudalidade e favor em artes na 'Belle Époque' chilena”, Mónica González García aplicou as noções cunhadas por Schwarz para entender a literatura do seu país.

Em maior volume, os artigos que privilegiaram os princípios teóricos da reflexão schwarziana, os diálogos e as filiações intelectuais, compõem um conjunto igualmente matizado. "A inautenticidade como inflexão no esquema de Schwarz", do sociólogo Edson Farias, construiu detida análise sobre a obra de Schwarz dedicada a Machado de Assis, salientando dimensões do método e as referências analíticas mais importantes. "Nacional por negação: ensaio e crítica independente no último Roberto Schwarz”, de autoria de Fabio Mascaro Querido, caracterizou os diálogos e a contribuição crítica do intelectual no tratamento dos impasses no curso do processo de formação da nação. Nessa mesma linha, Luiz Philipe de Caux e Felipe Catalani trabalharam a linhagem dos estudos sobre a formação da nacionalidade, da qual o filósofo Paulo Arantes é reconhecido intérprete, no texto "A passagem do dois ao zero: dualidade e desintegração no pensamento dialético brasileiro (Paulo Arantes, leitor de Roberto Schwarz)”. Karim Helayel e Antonio Brasil Jr. chamaram a atenção para a presença da sociologia da USP na obra do crítico, especialmente do grupo congregado em torno de Florestan Fernandes, no texto sobre "Roberto Schwarz e a sociologia paulista dos anos I960". Por fim, Luiz Gustavo da Cunha de Souza, em "Usos do reconhecimento em Roberto Schwarz: tentativa de uma aproximação”, identificou a noção de reconhecimento, formulada por Axel Honneth, à categoria do favor, construída para tratar da torção ideológica dos princípios liberais aportados no Brasil escravista.

Como se vê, a recente fortuna crítica da obra de Roberto Schwarz caracteriza-se por mirar outros horizontes, mais consoantes às questões atuais das pesquisas sobre a cultura e a vida intelectual. Alguns traços persistentes podem ser, todavia, notados. Os artigos que compõem o Dossiê são ensaios que analisam o moderno ensaísmo 
nascido da pena de Roberto Schwarz. Sinalizam, por decorrência, assimilação e renovação do estilo. A teoria crítica, especialmente na vertente adorniana, serviu tanto para evidenciar o tributo de Schwarz a essa corrente intelectual, quanto para frisar o rendimento derivado dessa escolha analítica. Surpreende a discreta presença de Pierre Bourdieu, reconhecidamente o autor preponderante no campo das pesquisas atuais sobre a cultura. Confirma-se, por fim, a importância da obra de Roberto Schwarz na compreensão dos impasses do Brasil contemporâneo, desvelados neste momento francamente regressivo da sociedade brasileira. Por esse e outros relevantes motivos, a visão crítica de Schwarz tem resistido ao tempo, continuando a inspirar os jovens pesquisadores que a ela recorrem, motivados pelo desejo de esclarecer os nossos dilemas e se elevarem intelectualmente.

SOBRE A AUTORA

\section{MARIA ARMINDA DO NASCIMENTO ARRUDA é}

professora titular do Departamento de Sociologia da

Faculdade de Filosofia, Letras e Ciências Humanas da

Universidade de São Paulo (FFLCH/USP).

E-mail: arr@usp.br

https://orcid.org/oooo-0002-I609-6743

\section{REFERÊNCIAS}

CANDIDO, Antonio. Sobre Roberto Schwarz. In: CEVASCO, Maria Elisa; OHATA, Org.). Um crítico na periferia do capitalismo: reflexões sobre a obra de Roberto Schwarz. São Paulo: Companhia das Letras, 2007, p. I4-I5.

CEVASCO, Maria Elisa; OHATA, Milton (Org.). Um crítico na periferia do capitalismo: reflexões sobre a obra de Roberto Schwarz. São Paulo: Companhia das Letras, 2007.

SCHWARZ, Roberto. As ideias fora do lugar. In: . Ao vencedor as batatas: forma literária e processo social no início do romance brasileiro. São Paulo: Duas Cidades, I977, p. 9-32.

Sobre Adorno. In: . Martinha versus Lucrécia: ensaios e entrevistas. São Paulo: Companhia das Letras, 20I2, p. 44-5I. 